\title{
Effects of Deposition Parameters of Hydrothermal Method on Synthesis of ZnO-based Nanowires
}

\author{
Ya-Fen Wei, ${ }^{1,2}$ Wen-Yaw Chung, ${ }^{2}$ Cheng-Fu Yang, ${ }^{3 *}$ \\ Wei-Fan $\mathrm{Hsu}^{3}$ and Chih-Cheng Chen ${ }^{1 * *}$ \\ ${ }^{1}$ School of Information Engineering, Jimei University, Xiamen, Fujian 361021, China \\ ${ }^{2}$ Department of Electronic Engineering, Chung Yuan Christian University, Taoyuan City 320, Taiwan \\ ${ }^{3}$ Department of Chemical and Material Engineering, National University of Kaohsiung, Kaohsiung 811, Taiwan
}

(Received May 5, 2019; accepted September 4, 2019)

Keywords: hydrothermal method, concentration, $\mathrm{Zn}\left(\mathrm{NO}_{3}\right)_{2} \cdot 6 \mathrm{H}_{2} \mathrm{O}, \mathrm{ZnO}$-based nanowires, growth time

$\mathrm{ZnO}$-based nanomaterials can be used as sensors for different applications, including gas and ultraviolet (UV) ray sensors. To grow $\mathrm{ZnO}$ nanowires by the hydrothermal method, a $\mathrm{ZnO}$ seed layer was prepared by a sputtering method to deposit $\mathrm{ZnO}$ films on $\mathrm{SiO}_{2} / \mathrm{Si}$ substrates of about $200 \mathrm{~nm}$ thickness. Next, $\mathrm{Zn}\left(\mathrm{NO}_{3}\right)_{2} \cdot 6 \mathrm{H}_{2} \mathrm{O}$ and $\mathrm{C}_{6} \mathrm{H}_{12} \mathrm{~N}_{4}$ were used as reagents, and DI water was used as a solvent, and they were mixed to the designed compositions. We found that when $\mathrm{Zn}\left(\mathrm{NO}_{3}\right)_{2} \cdot 6 \mathrm{H}_{2} \mathrm{O}$ and $\mathrm{C}_{6} \mathrm{H}_{12} \mathrm{~N}_{4}$ were used as reagents to grow $\mathrm{ZnO}$ nanostructured materials, growth temperature, the concentration of the diluted solution, growth time, and the position of the substrates were four important factors affecting the synthesis results. The surface morphologies of $\mathrm{ZnO}$ nanowires were observed by field-emission scanning electron microscopy (FESEM), and crystalline phases were analyzed using X-ray diffraction (XRD) patterns. The FESEM images and XRD patterns were used to determine the effects of synthesis parameters on the morphologies and crystalline properties of the grown nanostructured materials. First, we found that $100{ }^{\circ} \mathrm{C}$ was the optimum synthesis temperature for growing pure $\mathrm{ZnO}$ nanowires, because $\mathrm{ZnO}$-based nanowires could be successfully synthesized at different concentrations of $\mathrm{Zn}\left(\mathrm{NO}_{3}\right)_{2} \cdot 6 \mathrm{H}_{2} \mathrm{O}$ and $\mathrm{C}_{6} \mathrm{H}_{12} \mathrm{~N}_{4}$ and different synthesis times. The effects of growth time, the position of the substrates on the carry sheet glass, and concentrations of $\mathrm{Zn}\left(\mathrm{NO}_{3}\right)_{2} \cdot 6 \mathrm{H}_{2} \mathrm{O}$ and $\mathrm{C}_{6} \mathrm{H}_{12} \mathrm{~N}_{4}$ on the growth of nanostructured materials were also investigated.

\section{Introduction}

Nowadays, it is necessary to investigate gas sensors for detecting volatile and toxic gases existing in the environment because of environmental and atmospheric pollutions and the requirements for the safety of factories and daily life. One-dimensional (1D) and twodimensional (2D) $\mathrm{ZnO}$ nanostructures have attracted considerable interest because they have a large surface-to-volume ratio, which enables them to absorb more gases or test molecules or accept more measured gases or signals on their surfaces; thus, they can act as highly efficient

\footnotetext{
*Corresponding author: e-mail: cfyang@nuk.edu.tw

*** Corresponding author: e-mail: 201761000018@jmu.edu.cn https://doi.org/10.18494/SAM.2019.2506
} 
sensors. ZnO-based nanostructured materials can be used as one of the promising materials for gas sensors to detect different volatile and toxic gases because of their electrochemical stability, nontoxicity, and low cost. ${ }^{(1-3)} \mathrm{ZnO}$-based nanorods (or nanowires) are an excellent group of quasi-1D nanostructured materials.

There are many different physical and chemical methods of growing or synthesizing $\mathrm{ZnO}-$ based nanostructured materials. However, conventional methods need strictly controlled synthesis environments, complicated procedures, and expensive equipment, and some hightemperature synthesis processes. ${ }^{(4,5)}$ For example, Scalisi et al. used metal organic chemical vapor deposition (MOCVD) to grow high-quality $\mathrm{ZnO}$ nanomaterials on various substrates. ${ }^{(6)}$ However, the MOCVD system is expensive, has problems with toxic gases, and requires sensors for alarm to release toxic gases. The decomposition of zinc acetate dihydrate $\left(\mathrm{Zn}\left(\mathrm{CH}_{3} \mathrm{COO}\right)_{2}\right)$ was investigated to fabricate high-purity $\mathrm{ZnO}$ nanowires in air ambient, but the precursors need to be decomposed at $300{ }^{\circ} \mathrm{C}^{(7)}$ In contrast to the above mentioned techniques, using an aqueous solution to synthesize and grow $\mathrm{ZnO}$-based nanowires is a simpler and more cost-effective technique. This technique does not only have these disadvantages of expensive equipment, rigorous conditions, and complex processes, but also low-yield growth and high synthesis temperature.

The hydrothermal method is one of the most popular techniques using an aqueous solution to grow $\mathrm{ZnO}$ nanowires at low temperatures, and many different reagents have been used in this method. For example, Niarchos et al. used an alternative aqueous chemical growth (ACG) process to investigate a reliable and low-cost method, and they could grow large-scale $\mathrm{ZnO}$ nanorods on patterned Si substrates by a low-temperature process. ${ }^{(8)} \mathrm{Li}$ et al. used $\mathrm{Zn}$ foil and an aqueous $\mathrm{Na}_{2} \mathrm{C}_{2} \mathrm{O}_{4}$ solution to successfully synthesize ultralong $\mathrm{ZnO}$ nanowires by a simple hydrothermal reaction at $140{ }^{\circ} \mathrm{C} .{ }^{(9)}$ They also found that the grown $\mathrm{ZnO}$ nanowires could be used as sensors for $\mathrm{NH}_{3}$ and $\mathrm{N}\left(\mathrm{C}_{2} \mathrm{H}_{5}\right)_{3}$ vapors, and showed excellent response characteristics towards low concentrations of $\mathrm{NH}_{3}$ and $\mathrm{N}\left(\mathrm{C}_{2} \mathrm{H}_{5}\right)_{3}$ vapors. The detection limits for $\mathrm{NH}_{3}$ and $\mathrm{N}\left(\mathrm{C}_{2} \mathrm{H}_{5}\right)_{3}$ vapors at the working temperature of $180{ }^{\circ} \mathrm{C}$ are about 0.2 and $0.15 \mathrm{ppm}$, respectively. (9) Moreover, Hsu et al. used a vapor solid method to synthesize $\mathrm{ZnO}$ films at a temperature range of $400-700{ }^{\circ} \mathrm{C}$ on $\mathrm{Si}$ substrates and investigated them as humidity sensors. ${ }^{(10)} \mathrm{ZnO}$ nanostructures could also be grown on glass and $\mathrm{SiO}_{2} / \mathrm{Si}$ substrates from an equimolar aqueous solution of $\mathrm{Zn}\left(\mathrm{NO}_{3}\right)_{2} \cdot 6 \mathrm{H}_{2} \mathrm{O}$ and $\mathrm{C}_{6} \mathrm{H}_{12} \mathrm{~N}_{4}$ at temperatures below $100{ }^{\circ} \mathrm{C} .{ }^{(11-14)}$ Thus, the concentrations of $\mathrm{Zn}\left(\mathrm{NO}_{3}\right)_{2} \cdot 6 \mathrm{H}_{2} \mathrm{O}$ and $\mathrm{C}_{6} \mathrm{H}_{12} \mathrm{~N}_{4}$ in deionized (DI) water were an important factor affecting the growth properties of the synthesized $\mathrm{ZnO}$-based nanostructured materials.

Previously, we successfully investigated a two-step method of synthesizing pure $\mathrm{ZnO}$ nanostructured materials, where the sputtering method was used to deposit the seed $\mathrm{ZnO}$ films and the hydrothermal method was used to grow nanowires (nanorods) and nanoflowers. ${ }^{(12)}$ Because we used $\mathrm{Zn}\left(\mathrm{NO}_{3}\right)_{2} \cdot 6 \mathrm{H}_{2} \mathrm{O}$ and $\mathrm{C}_{6} \mathrm{H}_{12} \mathrm{~N}_{4}$ as reagents and $\mathrm{Eu}\left(\mathrm{NO}_{3}\right)_{3} \cdot 6 \mathrm{H}_{2} \mathrm{O}$ or $\mathrm{In}\left(\mathrm{NO}_{3}\right)_{2} \cdot 6 \mathrm{H}_{2} \mathrm{O}$ as the dopant, we could synthesize Eu- and In-doped $\mathrm{ZnO}$ nanowires by the hydrothermal method. We also had found important novelties that the concentrations of $\mathrm{Eu}^{3+}$ and $\mathrm{In}^{3+}$ ions could reduce the required synthesis temperatures of $\mathrm{ZnO}$-based nanowires and enhance their photoluminescence excitation (PLE) and photoluminescence (PL) emission properties. ${ }^{(13,14)}$ We also found that if $\mathrm{Zn}\left(\mathrm{NO}_{3}\right)_{2} \cdot 6 \mathrm{H}_{2} \mathrm{O}$ and $\mathrm{C}_{6} \mathrm{H}_{12} \mathrm{~N}_{4}$ were used as reagents 
to grow the $\mathrm{ZnO}$ nanostructured materials, the concentration of the diluted solution, growth temperature, growth time, and the position of the substrates were the important factors affecting the synthesis results. We would investigate the effects of these parameters on the morphologies and crystalline structures of the synthesized $\mathrm{ZnO}$-based nanomaterials.

\section{Experimental Procedure}

Many studies have shown that to synthesize and uniformly grow highly c-oriented $\mathrm{ZnO}$ nanorods (nanowires), a low-temperature hydrothermal method of forming a $\mathrm{ZnO}$ seed layer is necessary. ZnO powder (purity $99.999 \%$ ) was used as a raw material and polyvinyl alcohol (PVA) was used as the binder. After mixing $\mathrm{ZnO}$ and PVA, the mixture was pressed into pellets of $6 \mathrm{~mm}$ thickness and $56 \mathrm{~mm}$ diameter, and the pellets were heated to $600{ }^{\circ} \mathrm{C}$ to debinder PVA. Each pellet was sintered at $1100{ }^{\circ} \mathrm{C}$ for $2 \mathrm{~h}$ to form the $\mathrm{ZnO}$ ceramic target. The $\mathrm{SiO}_{2} /$ $\mathrm{Si}$ substrates were cleaned with DI water, acetone, and isopropyl alcohol. The RF magnetron sputtering method was used to deposit the $\mathrm{ZnO}$ seed layers on $\mathrm{SiO}_{2} / \mathrm{Si}$ substrates. Then, the $\mathrm{ZnO} / \mathrm{SiO}_{2} / \mathrm{Si}$ layers and the hydrothermal technique were used as the substrates and method, respectively, to grow pure (undoped) $\mathrm{ZnO}$ nanowires. Previously, we used a well-designed structure to grow $\mathrm{ZnO}$-based nanostructured materials by a hydrothermal method. ${ }^{(12-14)}$ In this study, we also used the designed structure to grow $\mathrm{ZnO}$-based nanostructured materials and investigated growth temperature, the concentration of the diluted solution, growth time, and the position of the substrates. We used $\mathrm{Zn}\left(\mathrm{NO}_{3}\right)_{2} \cdot 6 \mathrm{H}_{2} \mathrm{O}$ and $\mathrm{C}_{6} \mathrm{H}_{12} \mathrm{~N}_{4}$ as reagents and the hydrothermal method to synthesize $\mathrm{ZnO}$-based nanostructured materials. We also investigated the effects of growth time, the position of the substrates, and concentrations of $\mathrm{Zn}\left(\mathrm{NO}_{3}\right)_{2} \cdot 6 \mathrm{H}_{2} \mathrm{O}$ and $\mathrm{C}_{6} \mathrm{H}_{12} \mathrm{~N}_{4}$ to determine their relationships with the growth of nanostructured materials. First, $\mathrm{Zn}\left(\mathrm{NO}_{3}\right)_{2} \cdot 6 \mathrm{H}_{2} \mathrm{O}$ and $\mathrm{C}_{6} \mathrm{H}_{12} \mathrm{~N}_{4}$ were mixed with DI water with the desired compositions of $0.01,0.05$, and $0.1 \mathrm{M}$. The $\mathrm{ZnO}$ nanomaterials were also synthesized at temperatures of 80 , 100 , and $120{ }^{\circ} \mathrm{C}$ with different durations by a hydrothermal method. Also, the positions of the $\mathrm{SiO}_{2} / \mathrm{Si}$ substrates on the carry sheet glass are shown in Fig. 1. The crystalline structures of the synthesized $\mathrm{Ca}_{2} \mathrm{ZnMoO}_{6}$ powders were measured using X-ray diffraction (XRD)

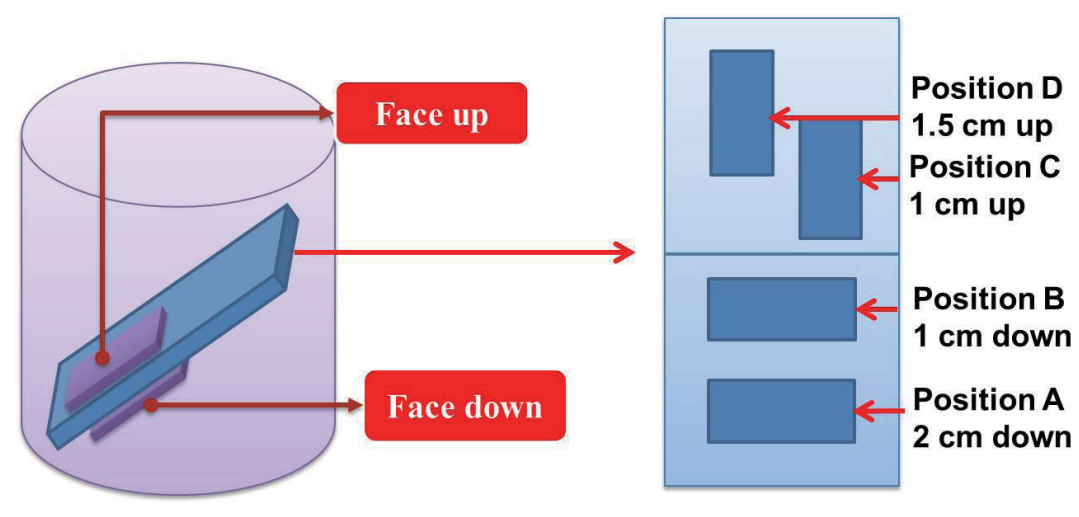

Fig. 1. Positions of $\mathrm{SiO}_{2} / \mathrm{Si}$ substrates on carry sheet glass. 
patterns with $\mathrm{Cu} \mathrm{K} \alpha$ radiation $(\lambda=1.5418 \AA)$ at a scanning speed of $2^{\circ}$ per min. Scanning electron microscopy was carried out to observe the morphologies of all the synthesized $\mathrm{ZnO}$ nanomaterials with an acceleration voltage of $10 \mathrm{kV}$.

\section{Results and Discussion}

The general surface morphologies of the hydrothermally synthesized $\mathrm{ZnO}$ nanomaterials were examined by field-emission scanning electron microscopy (FESEM). Figure 2 shows the surface morphologies of the $\mathrm{ZnO}$ nanomaterials with different magnifications and synthesized at different durations, and the solution was $0.01 \mathrm{M}$ with face up at position $\mathrm{D}$. As shown in Fig. 1, regardless of whether the $\mathrm{ZnO} / \mathrm{SiO}_{2} / \mathrm{Si}$ substrates were face down (not shown here) or face up, no $\mathrm{ZnO}$ nanowires were formed and nanoscale particles were formed and dispersed on the surfaces of the substrates. When the growth time was $3 \mathrm{~h}$, as shown in Figs. 2(a) and 2(b), microscale rhombus or lozenge particles were formed, and as more rhombus or lozenge particles aggregated together, they would form a microscale flower. When the synthesis time was increased to $5 \mathrm{~h}$, as shown in Figs. 2(c) and 2(d), the lengths of the microscale rhombus or lozenge particles increased and the particles changed into microscale cicada-pupa-structured particles. As shown in Figs. 2(b) and 2(d), the rhombus or cicada-pupa-structured particles were bound with the nondiscerned nanowires, which did not have hexagonal prismatic structures.

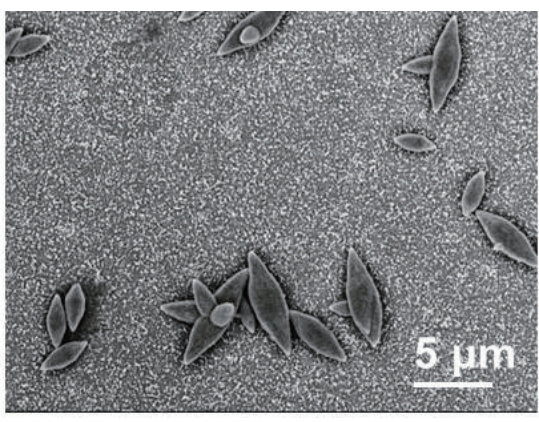

(a)

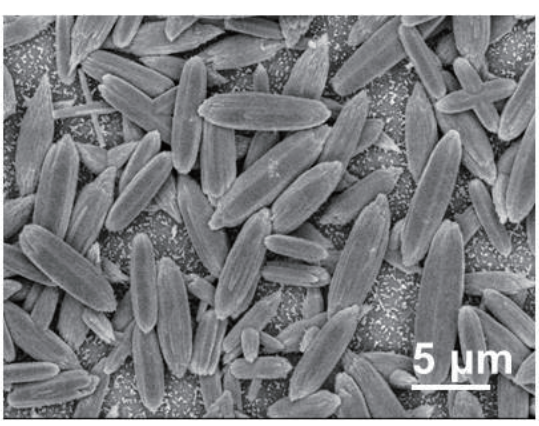

(c)

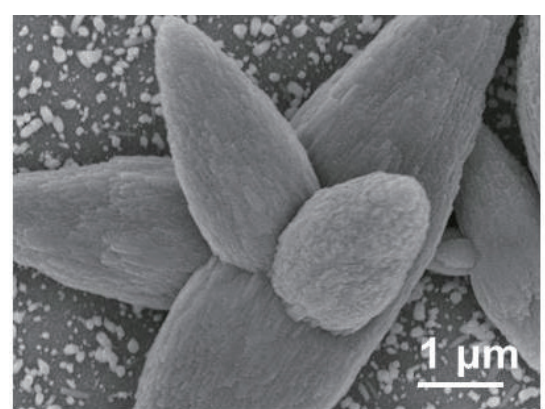

(b)

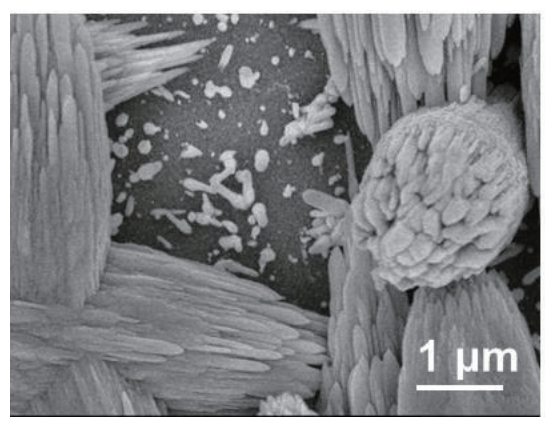

(d)

Fig. 2. Surface morphologies of $\mathrm{ZnO}$ films with different magnifications and synthesized at different durations. The solution was $0.01 \mathrm{M}$ with face up. (a) and (b) $3 \mathrm{~h}$ with lower and higher magnifications and (c) and (d) $5 \mathrm{~h}$ with lower and higher magnifications, respectively. 
To grow $\mathrm{ZnO}$ nanomaterials, $\mathrm{Zn}\left(\mathrm{NO}_{3}\right)_{2} \cdot 6 \mathrm{H}_{2} \mathrm{O}$ [or $\mathrm{Zn}\left(\mathrm{NO}_{3}\right)_{2}$ ] was used as the source material. When hexamethylenetetramine $\left[\left(\mathrm{CH}_{2}\right)_{6} \mathrm{~N}_{4}, \mathrm{HMT}\right]$ was added into the solution at room temperature, no precipitates were formed and sank to deposit on the substrates as they were initially mixed. When the temperature was increased to around $100{ }^{\circ} \mathrm{C}$, the HMT began to decompose into $\mathrm{NH}_{3}$ and $\mathrm{HCHO}$, and $\mathrm{OH}^{-}$ions were formed because $\mathrm{NH}_{3}$ would react with $\mathrm{H}_{2} \mathrm{O}$ to form $\mathrm{NH}_{3} \cdot \mathrm{H}_{2} \mathrm{O}$ and then decomposed into $\mathrm{NH}^{4+}$ and $\mathrm{OH}^{-}$ions. The $\mathrm{Zn}^{2+}$ ions would react with $\mathrm{OH}^{-}$and $\mathrm{Zn}(\mathrm{OH})_{2}$ precipitated. Because the mixed solution was heated, $\mathrm{Zn}(\mathrm{OH})_{2}$ would decompose into $\mathrm{ZnO}$ and $\mathrm{H}_{2} \mathrm{O}$, and $\mathrm{ZnO}$ nuclei precipitated and were synthesized to form the $\mathrm{ZnO}$ nanomaterials on the substrates. These can be represented by the following reactions:

$$
\begin{gathered}
\left(\mathrm{CH}_{2}\right)_{6} \mathrm{~N}_{4}+6 \mathrm{H}_{2} \mathrm{O} \leftrightarrow 4 \mathrm{NH}_{3}+6 \mathrm{HCHO}, \\
\mathrm{NH}_{3}+\mathrm{H}_{2} \mathrm{O} \leftrightarrow \mathrm{NH}_{3} \cdot \mathrm{H}_{2} \mathrm{O} \\
\mathrm{NH}_{3} \cdot \mathrm{H}_{2} \mathrm{O} \leftrightarrow \mathrm{NH}^{+4}+\mathrm{OH}^{-} \\
\mathrm{Zn}^{2+}+2 \mathrm{OH}^{-} \leftrightarrow \mathrm{Zn}(\mathrm{OH})_{2} \\
\mathrm{Zn}(\mathrm{OH})_{2} \leftrightarrow \mathrm{ZnO}+\mathrm{H}_{2} \mathrm{O}
\end{gathered}
$$

The theorem of the hydrothermal method uses low temperatures and high pressures to obtain nondissolved or hardly dissolved solutes depending on their dissolutions in water. If the solutes used can be easily dissolved in water, for example, nitrates $\left[\mathrm{Zn}\left(\mathrm{NO}_{3}\right)_{2} \cdot 6 \mathrm{H}_{2} \mathrm{O}\right.$ is used in this study], their concentrations can be easily controlled and the hydrothermal temperatures will be lower. When the hydrothermal method is used to synthesize the ZnO-based nanomaterials, the difference in temperature in the hydrothermal bottle will cause the water convection to form the saturated solution and then precipitates will grow into the designed crystals. During the precipitate concentration, temperature, hydrogen ion exponent $(\mathrm{PH})$, and the amount of added dopant are the parameters for controlling the growth of (hetero-) nucleation on the substrates. Liu et al. found that when the hydrothermal method was used to synthesize the $\mathrm{ZnO}$ nanostructured materials, the hydrophilic terminal hydroxyl groups of polyethylene glycol would be adsorbed on HMT-chelated Zn oligomers. ${ }^{(15)}$ For that, the rather hydrophobic oxyethylene chain would be exposed to the 2-methoxyethanol and the micelles formed would act as microreactors, in which the $\mathrm{Zn}$ oligomers were enveloped. ${ }^{(15)}$ Because of that, the $\mathrm{ZnO}$ nanowires were not easily formed. As the composition was $0.01 \mathrm{M}$, the concentration was very low, and the $\mathrm{ZnO}$ based nanomaterials could not grow or be synthesized in the vertical direction and could only precipitate and aggregate in the horizontal direction.

To investigate the effect of synthesis temperature on the growth properties of hydrothermally grown $\mathrm{ZnO}$ nanomaterials, the synthesis temperature was set at $120^{\circ} \mathrm{C}$. Previously, we found that when undoped $\mathrm{ZnO}$ nanomaterials were grown at $80{ }^{\circ} \mathrm{C}$, no $\mathrm{ZnO}$ nanowires were formed on the $\mathrm{ZnO} / \mathrm{SiO}_{2} / \mathrm{Si}$ substrates and only irregular $\mathrm{ZnO}$ nanoparticles were observed (not shown here). ${ }^{(14)}$ When the synthesis temperature was $100{ }^{\circ} \mathrm{C}, \mathrm{ZnO}$ nanowires were successfully grown 
on the $\mathrm{ZnO} / \mathrm{SiO}_{2} / \mathrm{Si}$ substrates, and the diameters of the synthesized $\mathrm{ZnO}$ nanowires were in the range of 80-120 nm (not shown here). ${ }^{(14)}$ The surface morphologies of the $120{ }^{\circ} \mathrm{C}$-synthesized $\mathrm{ZnO}$ nanomaterials are shown in Fig. 3(a) with face up and in Fig. 3(b) with face down, and the solution used was $0.1 \mathrm{M}$, the synthesis time was $3 \mathrm{~h}$, and the substrate was located at point D (Fig. 1). As shown in Fig. 3(a), only disk-type particles were observed, and as shown in Fig. 3(b), large aggregated particles were formed on the nanoscale particles. However, the $\mathrm{ZnO}$ nanowires were not synthesized and formed as the synthesis temperature was $120^{\circ} \mathrm{C}$. The reasons for this are that the $\mathrm{ZnO}$ nuclei precipitate rapidly, they have insufficient time to carry out the self-assembly process, and no $\mathrm{ZnO}$ nanowires were formed.

The surface morphologies of the $\mathrm{ZnO}$ nanomaterials with a synthesis time of $3 \mathrm{~h}$, a temperature of $100{ }^{\circ} \mathrm{C}$, a solution of $0.1 \mathrm{M}$, and $\mathrm{SiO}_{2} / \mathrm{Si}$ substrates at different positions on the carry sheet glass are shown in Fig. 4. When the $\mathrm{SiO}_{2} / \mathrm{Si}$ substrate was placed at points $\mathrm{A}$ and $\mathrm{B}$, the hexagonal prismlike microscale wires (or rods) in the horizontal direction were obtained. For the substrates located at points $\mathrm{A}$ and $\mathrm{B}$, the lengths of the microscale wires ranged from 5 to $17 \mu \mathrm{m}$ and 8 to $25 \mu \mathrm{m}$, as shown in Figs. 4(a) and 4(c), and the diameters were about 3 and $4 \mu \mathrm{m}$, as shown in Figs. 4(b) and 4(d), respectively. The results shown in Figs. 4(b) and 4(d) prove that the hexagonal prismlike rods are assembled or accumulated by the small nanoscale particles. A comparison of the results shown in Figs. 4(b) and 4(d) suggests that hexagonal prismlike rods with the substrate located at point A had poorer growth properties than those with the substrate located at point $\mathrm{B}$, and the reason will be discussed later.

Figure 5 shows the surface morphologies of the $\mathrm{ZnO}$ nanostructured materials with different magnifications. The synthesis time was $3 \mathrm{~h}$, the solution was $0.1 \mathrm{M}$, and the substrate was face up and located at point D. The SEM images of the sample shown in Fig. 5 reveal that not only the $\mathrm{ZnO}$ nanowires of 40-120 nm diameter were really observed, but also large particles or aggregated clusters were formed above the layer of uniform nanowires. The high-magnification image in Fig. 5(b) shows that the clusters were composed of rectangular or cubic crystals with a side length of 200-800 nm and Fig. 5(c) shows that the large particles also had rectangular or cubic structures with the a side length of 1200-2000 nm.

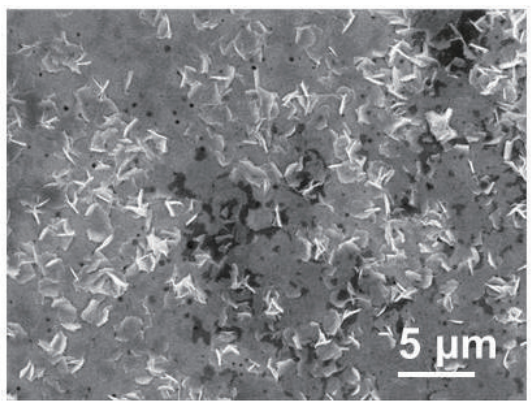

(a)

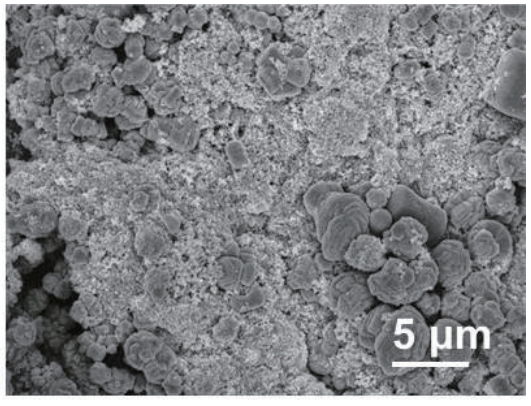

(b)

Fig. 3. Surface morphologies of $120^{\circ} \mathrm{C}$-synthesized $\mathrm{ZnO}$ nanomaterials. The solution was $0.1 \mathrm{M}$ with (a) face up and (b) face down. 


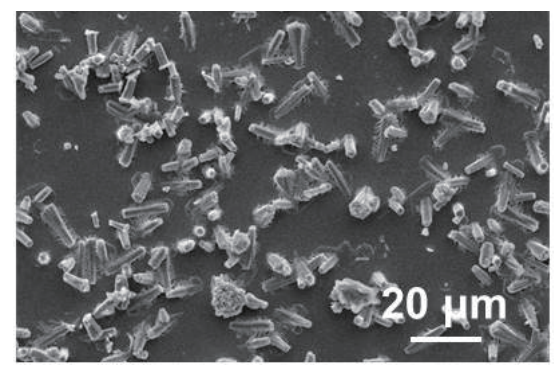

(a)

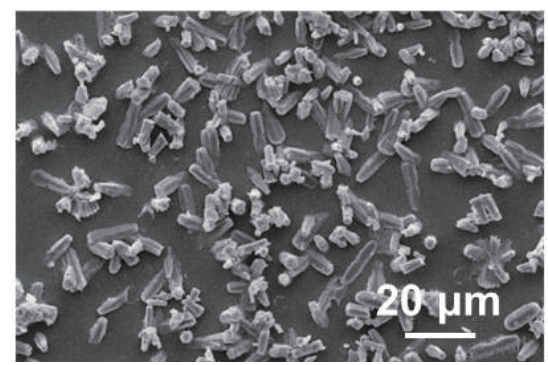

(c)

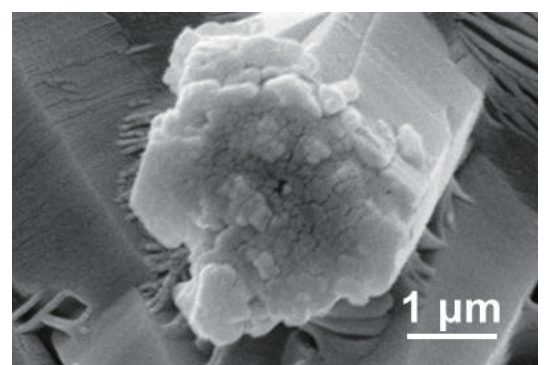

(b)

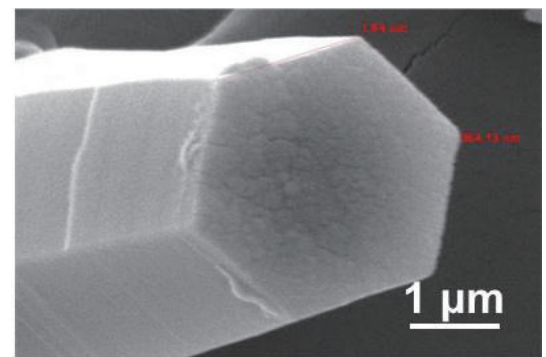

(d)

Fig. 4. Surface morphologies of $\mathrm{ZnO}$ nanomaterials with different magnifications. The synthesis time was $3 \mathrm{~h}$, the solution was $0.1 \mathrm{M}$, and the $\mathrm{SiO}_{2} / \mathrm{Si}$ substrates were located at different positions (Fig. 1) on the carry sheet glass. (a) and (b) Substrates located at position A. (c) and (d) Substrates located at position B.

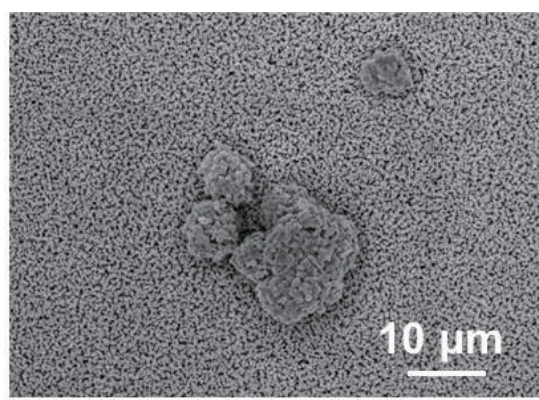

(a)

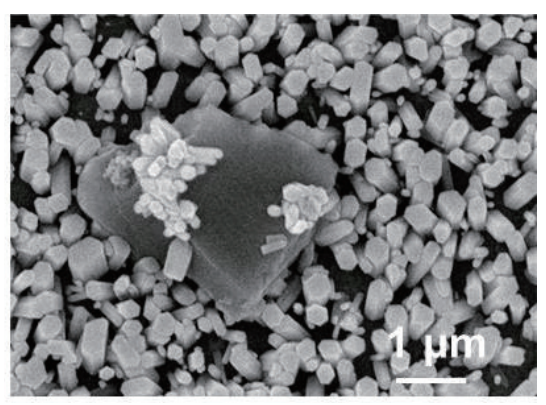

(c)

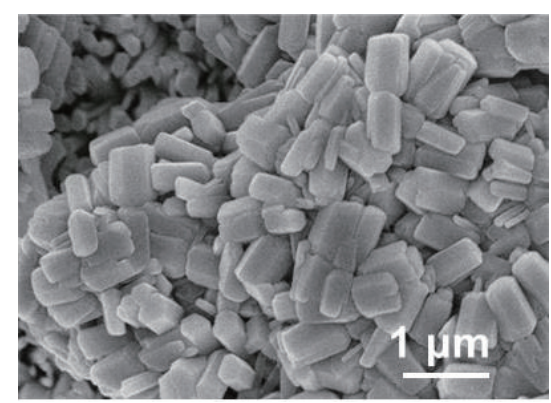

(b)

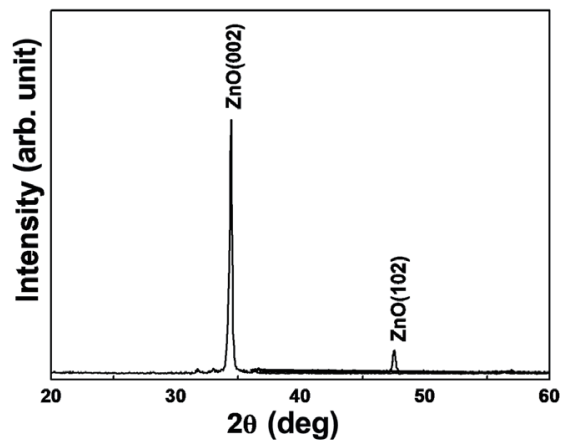

(d)

Fig. 5. Surface morphologies of the $\mathrm{ZnO}$ films with different magnifications. The synthesis time was $3 \mathrm{~h}$ and the solution was $0.1 \mathrm{M}$ and face up. (a) Low magnification, (b) and (c) high magnification at different positions, and (d) XRD pattern. 
Figure 5(d) shows the XRD patterns of the $\mathrm{ZnO}$ nanostructured materials shown in Figs. 5(a)-5(c). They show that the nanomaterials have a hexagonal wurtzite structure. The pattern is in agreement with the diffraction data from the standard card (JCPDS) with No. 36-1451. Even when the (102) diffraction peak coexisted with the (002) diffraction peak, the (002) diffraction peak has a higher diffraction intensity, suggesting that the nanomaterials are c-oriented. Thus, these results in Figs. 2-5 prove that synthesis temperature, face up or face down, and the position of the $\mathrm{SiO}_{2} / \mathrm{Si}$ substrate are the important parameters that affect the morphology as well as crystal orientation of the ZnO-based microscale or nanostructured materials. These results also suggest that if the substrate is located at a higher position (position $\mathrm{C}$ or D in Fig. 1), the hydrothermal method can be used to synthesize ZnO-based nanomaterials with better assembly and crystallization properties.

Figures 6 and 7 show the surface morphologies and XRD patterns of the $\mathrm{ZnO}$ nanomaterials with a synthesis time of $3 \mathrm{~h}$. The solution was $0.1 \mathrm{M}$ and face up, and the substrates were located at positions $\mathrm{C}$ and D, respectively. The results in Figs. 6(a) and 7(a) show that the $\mathrm{ZnO}$ nanowires were also formed and had a hexagonal wurtzite structure, with an easily discerned

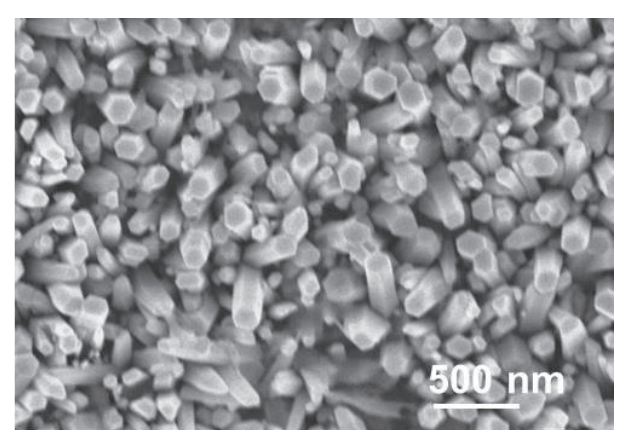

(a)

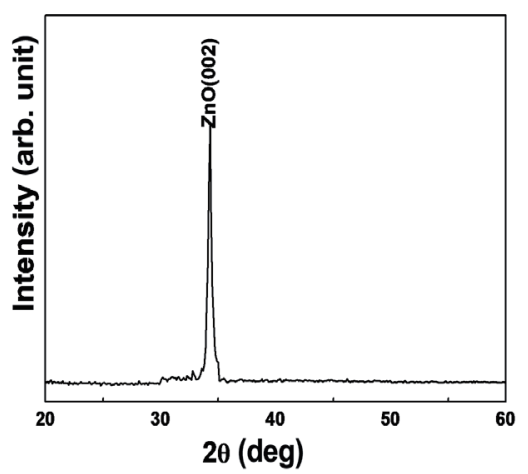

(b)

Fig. 6. (a) Surface morphology and (b) XRD pattern of $\mathrm{ZnO}$ nanomaterials with synthesis time of $3 \mathrm{~h}$. The solution was $0.1 \mathrm{M}$ and face up, and the substrates were located at position $\mathrm{C}$.

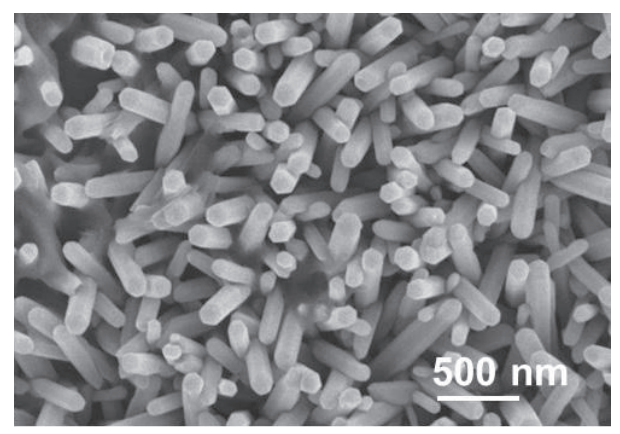

(a)

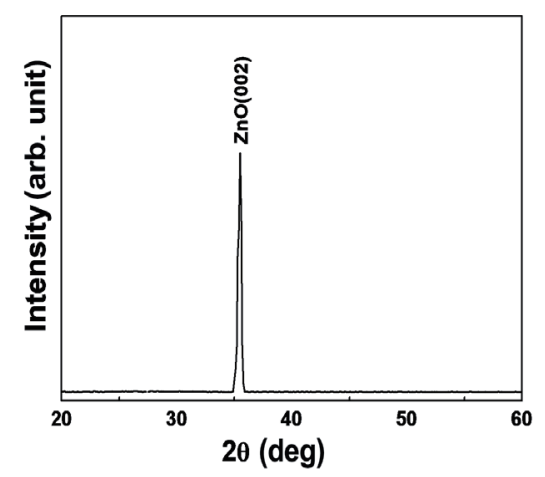

(b)

Fig. 7. (a) Surface morphology and (b) XRD pattern of $\mathrm{ZnO}$ nanomaterials with synthesis time of $3 \mathrm{~h}$. The solution was $0.1 \mathrm{M}$ and face up, and the substrates were located at position $\mathrm{D}$. 
hexagonal prism arrangement. The reason for the different morphologies of the synthesized $\mathrm{ZnO}$-based nanomaterials obtained on the two faces is related to the nucleation mechanism in the solution.

When the hydrothermal method is used to synthesize the nanomaterials, nucleation is the first step in the formation of either a new thermodynamic phase or a new structure via selfassembly or self-organization. Thus, as the $\mathrm{Zn}\left(\mathrm{NO}_{3}\right)_{2} \cdot 6 \mathrm{H}_{2} \mathrm{O}$ and $\mathrm{C}_{6} \mathrm{H}_{12} \mathrm{~N}_{4}$ solutions are used to synthesize $\mathrm{ZnO}$-based nanomaterials, two nucleation mechanisms, heterogeneous nucleation and homogeneous nucleation, will form during the synthesis process. ${ }^{(16)}$ In heterogeneous nucleation, the nucleus is at the surface, which is much more common than homogeneous nucleation. In this research, we have proven in Fig. 2 that as the concentration of $\mathrm{Zn}^{3+}$ ions is $0.01 \mathrm{M}$, the synthesis temperature is $100{ }^{\circ} \mathrm{C}$, and the $\mathrm{SiO}_{2} / \mathrm{Si}$ substrate is face up or face down. At the lower position of the solution (carry sheet glass), the heterogeneous nucleation in the horizontal direction dominates the synthesis results of the $\mathrm{ZnO}$ nanomaterials.

As the concentration of $\mathrm{Zn}^{3+}$ ions is $0.1 \mathrm{M}$, the synthesis temperature is $120{ }^{\circ} \mathrm{C}$, and the $\mathrm{SiO}_{2} / \mathrm{Si}$ substrate is face up or face down. At the upper positions (points $\mathrm{C}$ and $\mathrm{D}$ ) of the solution, the $\mathrm{ZnO}$ precipitate will deposit rapidly and no nucleation is formed. Because the nucleation mechanism cannot control the synthesis results of $\mathrm{ZnO}$ nanomaterials, no nucleation is formed during the self-assembly process and no $\mathrm{ZnO}$ nanomaterials are formed, as shown in Fig. 3. Thus, the results shown in Figs. 2-4 suggest that as the $\mathrm{SiO}_{2} / \mathrm{Si}$ substrate is face down and the other parameters are unchanged, the synthesis results of $\mathrm{ZnO}$ nanomaterials can be controlled by heterogeneous nucleation. When the concentration of $\left[\mathrm{Zn}(\mathrm{OH})_{4}\right]^{2-}$ ions is higher than the critical solubility, $\mathrm{Zn}^{2+}$ ions will directly transform into $\mathrm{ZnO}$ nuclei. ${ }^{(17,18)}$ After that, more $\left[\mathrm{Zn}(\mathrm{OH})_{4}\right]^{2-}$ complexes are preferably adsorbed and grow on the surfaces of $\mathrm{ZnO}$ nuclei, which are beneficial for enhancing the growth properties of $\mathrm{ZnO}$-based nanomaterials (or nanowires) along the c-axis direction; the XRD patterns shown in Figs. 6(a) and 7(a) prove these results. When the concentration of $\left[\mathrm{Zn}(\mathrm{OH})_{4}\right]^{2-}$ ions is relatively insufficient, the $\mathrm{C}_{6} \mathrm{H}_{12} \mathrm{~N}_{4}$ molecules will occupy the dominant position and serve as structure-directing and assembling agents to some extent, and result in the formation of nutlike, hexagonal spherelike, oblatelike, and flowerlike structures. ${ }^{(18,19)}$

\section{Conclusions}

We found that the synthesis temperature and time of $100{ }^{\circ} \mathrm{C}$ and for $3 \mathrm{~h}$, respectively, were the optimum parameters for growing pure $\mathrm{ZnO}$ nanowires. As the solution of $\mathrm{Zn}\left(\mathrm{NO}_{3}\right)_{2} \cdot 6 \mathrm{H}_{2} \mathrm{O}$ and $\mathrm{C}_{6} \mathrm{H}_{12} \mathrm{~N}_{4}$ was $0.01 \mathrm{M}$, microscale rhombus or lozenge particles were formed. When more rhombus or lozenge particles were aggregated, they would form a microscale flower. As $\mathrm{ZnO}$ nanomaterials were synthesized at $120^{\circ} \mathrm{C}$, with face up and face down, the solution of $0.1 \mathrm{M}$, and the synthesis time of $3 \mathrm{~h}$, only disk-type particles were observed and large aggregated particles were formed on the nanoscale particles. As the substrate was shifted from the lower position to the higher one, and the synthesis parameters were $100{ }^{\circ} \mathrm{C}$, with face up and face down, $0.1 \mathrm{M}$, and $3 \mathrm{~h}, \mathrm{ZnO}$ nanowires were also formed and had a hexagonal wurtzite structure, with an easily discerned hexagonal prism arrangement. 


\section{Acknowledgments}

This work was financially support by projects under Nos. MOST 108-2221-E-390-005 and MOST 108-2622-E-390-002-CC3.

\section{References}

1 L. W. Wang, Y. F. Kang, X. H. Liu, S. M. Zhang, W. P. Huang, and S. R. Wang: Sens. Actuators, B 162 (2012) 237.

2 S. Ozturk, N. K1lınc, I. Torun, A. Kosemen, Y. Sahin, and Z.Z. Ozturk: Inter. J. Hydrogen Energy 39 (2014) 5194.

3 H. Minaee, S. H. Mousavi, H. Haratizadeh, and P. W. de Oliveira: Thin Solid Films 545 (2013) 8.

4 P. C. Chang, Z. Y. Fan, D. W. Wang, W. Y. Tseng, W. A. Chiou, J. Hong, and J. G. Lu: Chem. Mater. 16 (2004) 5133.

5 Y. Y. Zhang, M. K. Ram, E. K. Stefanakos, and D. Y. Goswami: J. Nanomater. 2012 (2012) Article ID 624520.

6 A. A. Scalisi, R. G. Toro, G. Malandrino, M. E. Fragala, and G. Pezzotti: Chem. Vap. Deposition 14 (2008) 115.

7 C. C. Lin and Y. Y. Li: Mater. Chem. Phys. 113 (2009) 334.

8 G. Niarchos, E. Makarona, and C. Tsamis: Microsyst. Technol. 16 (2010) 669

9 L. Li, H. Yang, H. Zhao, J. Yu, J. H. Ma, L. J. An, amd X. W. Wang: Appl. Phys. A 98 (2010) 635.

10 N. F. Hsu, M. Chang, and C. H. Lin: Microsyst. Technol. 19 (2013) 1737.

11 G. Kenanakis, D. Vernardou, E. Koudoumas, and N. Katsarakis: J. Cryst. Growth 311 (2009) 4799.

12 Y. C. Chen, H. Y. Cheng, C. F. Yang, and Y. T. Hsieh: J. Nanomater. 2014 (2014) Article ID 430164.

13 W. J. Zheng, W. C. Tzou, J. R. Shen, C. F. Yang, and C. C. Chen: Sens. Mater. 31 (2019) 447.

14 Y. F. Wei, W. Y. Chung, C. F. Yang, J. R. Shen, and C. C. Chen: Electronics 8 (2019) 446.

15 X. X. Liu, Z. G. Jin, S. J. Bu, J. Zhao, and K. Yu: Mater. Sci. Eng. B 129 (2006) 139.

16 V. L. Snoeyink and D. Jenkins: Water Chemistry (John Wiley 8 Sons, New York, 1980).

17 W. J. Li, E. W. Shi, W. Z. Zhong, and Z. W. Yin: J. Cryst. Growth 201 (1999) 186.

18 L. Sun, R. Shao, Z. D. Chen, L. Q. Tang, Y. Dai, and J. F. Ding: Appl. Sur. Sci. 258 (2012) 5455.

19 R. Yi, N. Zhang, H. F. Zhou, R. R. Shi, G. Z. Qiu, and X. H. Liu: Mater. Sci. Eng. B 153 (2008) 25. 